\title{
Caracterización química foliar de los árboles de aguacate criollo (Persea americana var. drymifolia) en los bancos de germoplasma de Michoacán, México
}

\section{Foliar chemical caracterization of the creole avocado trees (Persea americana var. drymifolia) in the germplasm banks from Michoacán, Mexico}

\author{
Cintia A. Rincón-Hernández ${ }^{1,2}$, José De La Luz Sánchez Pérez ${ }^{3}$ y Francisco J. Espinosa-García ${ }^{1 *}$ \\ ${ }^{I}$ Centro de Investigaciones en Ecosistemas, Universidad Nacional Autónoma de México. Antigua carretera a Pátzcuaro 8701 , 58190 Morelia, \\ Michoacán, México. \\ ${ }^{2}$ Escuela de Químico Farmacobiología, Universidad Michoacana de San Nicolás de Hidalgo. 58030 Morelia, Michoacán, México. \\ ${ }^{3}$ Instituto de Investigaciones Químico-Biológicas, de la Universidad Michoacana de San Nicolás de Hidalgo, Edificio B-3, 58030 Morelia, Michoacán, \\ México. \\ "Correspondencia: espinosa@oikos.unam.mx
}

\begin{abstract}
Resumen. Persea americana var. drymifolia (aguacate criollo mexicano) se emplea como portainjerto en huertos de aguacate Hass y es fuente de genes de resistencia a plagas y patógenos para éste y otros cultivares. El aguacate criollo mexicano se está sustituyendo por cultivares comerciales o perdiendo por la destrucción de ecosistemas. Por eso, se estudiaron 250 árboles (52 accesiones de 14 estados de México); 247 de criollo mexicano y 3 híbridos de éste con P.shiedeana, P. americana var. americana y P. americana var. guatemalensis, plantados en los bancos de germoplasma en Michoacán. Se analizó la composición química mediante cromatografía de gases-masas. Hubo alta variabilidad química entre los árboles del banco de germoplasma con los 64 compuestos detectados. El análisis de cúmulos mostró 2 grandes grupos químicos con 100\% disimilitud y 22 grupos a 10\% de disimilitud. Los híbridos se agruparon de manera diferente a los árboles con características típicas de criollo y difieren en su altitud de origen. Corroboramos que los volátiles foliares sirven como marcadores para diferenciar los criollos típicos de sus híbridos y que mucha variación atribuida a la variedad criolla proviene de hibridaciones en zonas de contacto de esta variedad con otras variedades o especies de Persea.
\end{abstract}

Palabras clave: aguacate criollo, distribución geográfica de aguacate, estragol, híbridos de aguacate, metabolitos secundarios, variación química de aguacate.

\begin{abstract}
Persea americana var. drymifolia (mexican creole avocado) is used as rootstock in Hass avocado orchards and it is a source of genes for resistance to pests and pathogens for this and other cultivars. The Mexican varieties are being replaced by commercial cultivars or lost by the destruction of ecosystems. Therefore, we studied 250 avocado trees of 52 accessions from 14 Mexican states; 247 mexican creole avocado and 3 hybrids of that tree with $P$. shiedeana, P. americana var. americana or $P$. americana var. guatemalensis, planted at germplasm banks, Michoacán. Foliar chemical composition was analyzed by GC-MS. High chemical variability among the trees was found with the 64 volatile compounds detected. Two large chemical groups on a scale of $100 \%$ dissimilarity and 22 groups at $10 \%$ dissimilarity were found by cluster analysis. The hybrids were grouped differently from the typical creole trees and were also different in the altitude of origin. We corroborate that foliar volatiles serve as markers to differentiate creole avocado trees and their hybrids and that much variation attributed to the creole variety comes from hybridization in contact zones of this variety with other varieties or species of Persea.
\end{abstract}

Key words: creole avocado, avocado geographical distribution, estragole, hybrid avocados, foliar secondary metabolites, chemical variation of avocado.

\section{Introducción}

El árbol de aguacate Hass (Persea americana Mill. cv. Hass) se injerta en una variedad criolla (Persea americana

Recibido: 28 abril 2009; aceptado: 30 septiembre 2010 var. drymifolia (Schltdl. et Cham.) S. F. Blake, que es resistente a enfermedades de raíz. El uso de portainjertos de ésta u otras variedades criollas es la base de la producción de aguacate Hass en las principales áreas cultivadas en el mundo. La variedad criolla también es fuente de genes de resistencia a plagas y enfermedades para las variedades comerciales de aguacate (Sánchez-Pérez, 1999). Además, el fruto de la variedad drymifolia se consume localmente 
y tiene mucha demanda. El aguacate ( $P$. americana Mill., Lauraceae) tiene 3 variedades: antillano ( $P$. americana var. americana), guatemalteco ( $P$. americana var. guatemalensis L. O. Wms.) y criollo mexicano (P. americana var. drymifolia) (Popenoe, 1941; Bergh et al., 1973). Estas variedades se caracterizan por el tamaño y forma del fruto, textura y color de la cáscara, tamaño de la semilla y maduración del fruto, entre otras diferencias (Lahav y Lavi, 2002).

La clasificación taxonómica infraespecífica de Persea americana Mill. aún es tema de debate, pues la variedad que nos ocupa, también llamada "raza mexicana", fue descrita inicialmente como especie nueva por Schlechtendal y Chamisso en 1831 (Linnaea 6: 365. 1831) y después reducida a variedad de P. americana por S. F, Blake (J. Wash. Acad. Sci. 10: 15. 1920). Louis F. Williams sostuvo esta variedad y más tarde A. E. Murray la reconoció como subespecie (Kalmia 15: 17, 1985). Con respecto a la raza Guatemalteca, L. O. Williams la describió inicialmente como Persea nubigena L. O. Wms.var. guatemalensis (Econ. Bot. 31: 318. 1977), a partir de un individuo cultivado. Más tarde, R. W. Scora determinó que esta variedad pertenecía a P. americana (Avocado: Bot. 20. 2001), por lo que el nombre correcto quedó como $P$. americana Mill. var. guatemalensis ( L. O.Williams ) Scora.

No obstante que desde los años 80 se ha apoyado la integridad de las variedades botánicas a partir de estudios genéticos y químicos (Bergh et al., 1973; Furnier et al., 1990; Mhameed et al., 1997; Fiedler et al., 1998), y de que los árboles de estos taxa se encuentran en estado silvestre (algunos ferales) o cultivado, van der Weff (2002) desconoció todas estas variedades diciendo que eran "razas cultivadas" de $P$. americana; más aún, redujo a la sinonimia de $P$. americana a otras 10 especies o variedades, basándose exclusivamente en atributos morfológicos revisados visualmente, pero sin ningún análisis filogenético o multivariado.

Un análisis filogenético basado en caracteres morfológicos (Campos Rojas et al., 2006) determinó que muchas de las especies reducidas a la sinonimia por van der Weff (2002) merecían el estatus de especie y que las variedades o razas (mexicana y guatemalteca) de P. americana debían reconocerse como especies distintas, aunque habría que esperar los resultados filogenéticos que incluyeran datos moleculares como los ITS para validar esta propuesta. Es claro que existe la necesidad de una revisión taxonómica que incluya datos morfológicos, moleculares, químicos y filogeográficos para desenredar la taxonomía del subgénero Persea. Tal confusión ha dado como resultado una gran heterogeneidad en la manera de nombrar las variedades de aguacate: unas veces como variedades taxonómicas, otras como variedades cultivadas o razas, o bien como razas hortícolas. En este trabajo se manejan las entidades taxonómicas de $P$. americana como variedades botánicas para distinguirlas de los cultivares modernos ( $\mathrm{p}$. ej. Fuerte, Hass, Zutano, Bacon).

En los huertos, los árboles de Persea americana var. drymifolia, se están sustituyendo por variedades mejoradas o híbridos de alta productividad o se pierden por la destrucción de ecosistemas donde se encuentran en forma silvestre (Ben-Ya'acov et al., 1995; Sánchez-Pérez, 1999). Para atenuar el problema, diferentes instituciones han creado bancos de germoplasma de Persea, en los cuales se conservan árboles de diferente procedencia. Los bancos de germoplasma permiten la conservación de la variabilidad genética y el avance del conocimiento botánico y agronómico en el desarrollo de nuevos cultivares; también son una fuente de genes de resistencia contra plagas y enfermedades. Además de la variabilidad genética, se ha demostrado que la variabilidad química de una especie de planta está asociada a su susceptibilidad o resistencia a plagas y enfermedades (Rice et al., 1978; Sturgeon 1979; Langenheim et al., 1980; Gouyon et al., 1983; Langenheim et al., 1986; Cates y Redak, 1988; Linhart, 1991; Edwards et al., 1993; Espinosa-García, 2001; Langenheim, 2003).

Algunos estudios en Persea americana var. drymifolia muestran la actividad de algunos compuestos químicos contra varios de sus herbívoros y patógenos, especialmente los terpenoides y fenilpropanoides de las hojas (Sagrero-Nieves y Bartley, 1995; Rincón-Hernández y Espinosa-García, 2008). Como los terpenoides y otros metabolitos secundarios muestran un fuerte control genético, se han usado como marcadores químicos para describir variantes en especies y poblaciones de plantas (Rehfeldt, 1999; Adams, 2000; Otto y Wilde, 2001; Sabor y Skrzyszewaska, 2002; Adams et al., 2003; Nava-Cruz et al., 2006), incluidas las 3 variedades de $P$. americana (Wu et al., 2007). También han sido útiles como herramienta taxonómica en coníferas (Smith, 1983; Savage et al., 1994), como el género Abies, ya que han ayudado a delimitar especies e híbridos que antes habían sido clasificados como taxa diferentes de acuerdo a sus características morfológicas (Nava-Cruz et al., 2006).

En el género Persea, el fenilpropanoide estragol ha servido como marcador taxonómico para distinguir la variedad mexicana de otras variedades y para la identificación de híbridos (Scora y Bergh, 1992; Wu et al., 2007); otros monoterpenos y sesquiterpenos foliares fueron utilizados para distinguir la variedad guatemalensis de la variedad americana (Scora y Bergh, 1992; Scora y Scora, 1998; Scora y Scora 2000; Ogunbinu et al., 2007) y otras especies de Persea, como Persea dutheie (Padalia et al., 2009). En todos estos casos, la distinción de híbridos se ha basado en algunos compuestos y nunca en un perfil de 
terpenoides o fenilpropanoides.

La variación química foliar de aguacate Hass se ha estudiado en huertos comerciales (Espinosa-García et al., 2001) y en un banco de germoplasma de P. americana var. drymifolia en Celaya, Gunajuato que tiene accesiones de 7 estados de México (Torres-Gurrola et al., 2009), pero no en los bancos de germoplasma de Michoacán, que resultan importantes por que tienen accesiones de 14 estados del país. Por lo tanto, los objetivos de este estudio son: a) determinar la variación química de $P$. americana var. drymifolia, en los bancos de germoplasma INIFAP Michoacán; b) confirmar si los terpenoides foliares son una herramienta para diferenciar híbridos de $P$. americana var. drymifolia con $P$. shiedeana y las otras variedades de $P$. americana y $c$ ) identificar si existe relación entre el origen geográfico de las accesiones de aguacate y su composición química.

\section{Materiales y métodos}

El estudio se realizó en los bancos de germoplasma del Instituto Nacional de Investigaciones Forestales, Agrícolas y Pecuarias (INIFAP), ubicados en Uruapan (1924'26”N; 10203'08'O; Altitud 1620 m snm), Cupatitzio $\left(19^{\circ} 25^{\prime} 37^{\prime \prime} \mathrm{N} ; 1^{\circ} 102^{\circ} 04^{\prime} 26^{\prime \prime} \mathrm{O}\right.$; altitud $\left.1664 \mathrm{~m} \mathrm{snm}\right)$ y Apatzingán $\left(19^{\circ} 01^{\prime} 30^{\prime \prime} \mathrm{N}\right.$; $102^{\circ} 12^{\prime} 25^{\prime \prime} \mathrm{O}$; Altitud 360 $\mathrm{m} \mathrm{snm})$. En estos bancos se encuentran árboles de las 3 variedades de aguacates, híbridos y otras especies de Persea; todos procedentes de semilla (Sánchez-Pérez, 1999). Para nuestro estudio se emplearon los árboles de Persea americana var. drymifolia y 3 híbridos de la variedad drymifolia entre la variedad guatemalensis, la variedad americana y $P$. shiedeana, previamente caracterizados morfológicamente por Sánchez-Pérez (1999), los números de las accesiones pertenecientes al banco de germoplasma Apatzingán son A541, A582 y A271 respectivamente. Las accesiones analizadas proceden de los siguientes estados de la República Mexicana: Aguascalientes, Guanajuato, Hidalgo, Jalisco, México, Michoacán, Morelos, Nuevo León, Oaxaca, Puebla, Querétaro, San Luís Potosí, Tamaulipas y Veracruz. Los datos de origen de las accesiones fueron proporcionados por el Dr. Ignacio Vidales, Jefe del campo experimental INIFAP Uruapan.

Toma de muestras y colectas. Se analizó el perfil químico de 250 árboles de 52 accesiones de los bancos de germoplasma INIFAP (Cuadro 1). De cada árbol se tomaron 2 hojas jóvenes. Para este estudio es muy importante que la edad de las hojas sea similar, ya que el perfil químico varía de acuerdo con la ontogenia del tejido (Hartmann y Dierich, 1998). Los criterios empleados para identificar una hoja joven fueron el color verde brillante claro, y un menor grosor y mayor flexibilidad que el de las hojas maduras. Las colectas se realizaron entre el 29 de noviembre del 2003 y el 14 de febrero del 2004. Las muestras recolectadas se colocaron en una bolsa de plástico y se transportaron en un recipiente con hielo al laboratorio para su análisis químico. Análisis químico. Las hojas se dividieron a lo largo de la vena central y una mitad se deshidrató a $80^{\circ} \mathrm{C}$ durante un día para determinar el peso seco. La otra mitad se pesó en fresco y se colocó en un frasco ámbar con hexano, $1 \mathrm{mg}$ de tetradecano como estándar interno, durante una semana; después la muestra se trituró con nitrógeno líquido, se agregó el hexano del frasco, y se siguió moliendo y agregando hexano fresco hasta que el disolvente dejó de verse verde. La solución resultante se filtró con sulfato de sodio para secarla y se agregó pirogalol como agente antioxidante (Sigma-Aldrich). Después, la muestra se concentró con una corriente suave de $\mathrm{N}_{2}$ gaseoso hasta $0.5 \mathrm{~mL}$ y se colocó en un frasco perfumero que permaneció a $-20^{\circ} \mathrm{C}$, hasta completar su análisis químico. Se inyectó $1 \mu l$ de la muestra en un cromatógrafo de gases Agilent HP6890, con detector de ionización de flama (FID), con inyección dividida 60:1, equipado con una columna capilar HP 5 (fenilmetil-siloxano) de $30 \mathrm{~m}$ de longitud, con un diámetro interno de $0.25 \mathrm{~mm}$ y $0.25 \mu \mathrm{m}$ de recubrimiento. Las condiciones fueron las empleadas por Torres-Gurrola et al. (2009).

Algunas muestras se analizaron en un cromatógrafo de gases Agilent 6890 acoplado a un espectrómetro de masas Agilent 5973 (CG-MS), para determinar la identidad de los picos cromatográficos. Se usó la misma columna que en GC-FID, helio como gas acarreador y las siguientes condiciones: inyector, $250{ }^{\circ} \mathrm{C}$; presión en el inyector, 1.23 psi; flujo en el inyector, $63.3 \mathrm{~mL} / \mathrm{min}$; flujo de helio en la columna, $0.5 \mathrm{~mL} / \mathrm{min}$; presión de helio en la columna, 1.23 psi con una velocidad de flujo $1 \mathrm{ml} / \mathrm{min}$. La interfase entre el cromatógrafo y espectrómetro se mantuvo a $280^{\circ} \mathrm{C}$; el modo de ionización por impacto de electrones $(70 \mathrm{eV}) ; \mathrm{y}$ escaneo completo $(35-550 \mathrm{~m} / \mathrm{z})$. El programa de temperatura para el horno fue el que se empleó para las muestras analizadas en el GC-FID.

Identificación y cuantificación química. Para identificar los compuestos se compararon los espectros de masas de la biblioteca de espectros NIST 98 con los obtenidos a partir de las muestras. Cuando la concordancia de los espectros fue mayor al $95 \%$ se consideró una identificación adecuada. Para confirmar la identificación se prepararon soluciones de compuestos puros (Sigma-Aldrich) de linalool, $\alpha$-cubebeno, $\alpha$-pineno, $\beta$-pineno, mirceno, anetol, camfeno, nerolidol, $\beta$-cariofileno, limoneno, $\alpha$-humuleno, $\gamma$-terpineol, las cuales fueron inyectadas en CG-MS para corroborar sus tiempos de retención y que sus espectros 
Cuadro 1. Procedencia del material con clave o número de accesión de los bancos de germoplasma INIFAP y número de árboles estudiados en cada localidad. Clave de identificación: A, banco de germoplasma Apatzingán; B, Cupatzio y C, Uruapan, seguida del número de identificación de la accesión del banco de germoplasma ${ }^{1}$. El paréntesis indica el número de árboles con esa clave

\begin{tabular}{|c|c|c|c|c|c|}
\hline Localidad y Estado & $\begin{array}{l}\text { Núm. } \\
\text { de } \\
\text { árboles }\end{array}$ & Clave de identificación & Latitud $N$ & Longitud $O$ & $\begin{array}{l}\text { Altitud m } \\
\text { snm }\end{array}$ \\
\hline Aguascalientes, Ags. & 7 & $\begin{array}{l}\text { A356, A358, A359, A360,A361, } \\
\text { A362, A363 }\end{array}$ & $21^{\circ} 50^{\prime} 46^{\prime \prime}$ & $102^{\circ} 43^{\prime} 06^{\prime \prime}$ & 1640 \\
\hline Acambaro, Gto. & 4 & $\mathrm{~A} 348, \mathrm{~A} 35, \mathrm{~A} 350, \mathrm{~A} 352$ & $20^{\circ} 01^{\prime} 53^{\prime \prime}$ & $100^{\circ} 43^{\prime} 18^{\prime \prime}$ & 1860 \\
\hline Celaya, Gto. & 5 & A352, A353, A354, A355, A636 & $20^{\circ} 37^{\prime} 30^{\prime \prime}$ & $100^{\circ} 45^{\prime} 40^{\prime \prime}$ & 1770 \\
\hline Comonfort, Gto. & 7 & $\begin{array}{l}\text { A } 524, \text { A } 525, \text { B } 075, \text { B } 76, \text { B } 77, \text { B } 78, \\
\text { B } 079\end{array}$ & $20^{\circ} 45^{\prime} 50^{\prime \prime}$ & $100^{\circ} 45^{\prime} 25^{\prime}$ & 1790 \\
\hline Huehutla, Hgo. & 2 & $\mathrm{C} 280, \mathrm{C} 281$ & $21^{\circ} 08^{\prime} 25^{\prime \prime}$ & $98^{\circ} 25^{\prime} 12^{\prime \prime}$ & 140 \\
\hline Tecozautla, Hgo. & 2 & A301, A303 & $20^{\circ} 32^{\prime} 00^{\prime \prime}$ & $99^{\circ} 38^{\prime} 00^{\prime \prime}$ & 1700 \\
\hline Sta. Ma de los Angeles, Jal. & 1 & B016 & $22^{\circ} 10^{\prime} 15^{\prime \prime}$ & $103^{\circ} 13 ’ 25^{\prime}$ & 1700 \\
\hline Totatiche, Jal. & 1 & B012 & $21^{\circ} 55^{\prime} 38^{\prime \prime}$ & $103^{\circ} 26^{\prime} 35^{\prime \prime}$ & 1760 \\
\hline Villa Guerrero, Jal. & 1 & B015 & $21^{\circ} 55^{\prime} 38^{\prime \prime}$ & $103^{\circ} 35^{\prime} 37^{\prime \prime}$ & 1760 \\
\hline Amanalco, Edo. Mex. & 1 & A504 & $19^{\circ} 15^{\prime} 07^{\prime \prime}$ & $100^{\circ} 01 ' 11^{\prime \prime}$ & 2340 \\
\hline Donato Guerra, Edo.Mex. & 1 & A501 & $19^{\circ} 18^{\prime} 30^{\prime \prime}$ & $100^{\circ} 08^{\prime} 32^{\prime \prime}$ & 2200 \\
\hline Malinalco, Edo.Mex. & 13 & $\begin{array}{l}\text { A } 217, \text { A } 218, \text { A220, A222, A223, } \\
\text { A } 454, \text { A } 456(2), \text { A } 513, \text { A514, A51, } \\
\text { A646 }\end{array}$ & $18^{\circ} 56^{\prime} 54^{\prime \prime}$ & $99^{\circ} 29^{\prime} 41^{\prime \prime}$ & 1740 \\
\hline Ozumba de Zárate, Edo.Mex. & 8 & $\begin{array}{l}\text { B127, B128, A226, A227, A228, } \\
\text { A519, A520, A523 }\end{array}$ & $19^{\circ} 02^{\prime} 21^{\prime \prime}$ & $98^{\circ} 47^{\prime} 37^{\prime \prime}$ & 2340 \\
\hline Tenancingo, Edo. Mex. & 7 & A507, A508, A510, A511, A644 & $18^{\circ} 57^{\prime} 39^{\prime \prime}$ & $99^{\circ} 35^{\prime} 28^{\prime \prime}$ & 2020 \\
\hline Tepetlixpa, Edo. Mex. & 4 & $\mathrm{~A} 230, \mathrm{~A} 521, \mathrm{~A} 522(2)$ & $19^{\circ} 01^{\prime} 33^{\prime \prime}$ & $98^{\circ} 49^{\prime} 14^{\prime \prime}$ & 2300 \\
\hline Texcoco, Edo. Mex. & 1 & B123 & $19^{\circ} 30^{\prime} 20^{\prime \prime}$ & $98^{\circ} 52^{\prime} 55^{\prime \prime}$ & 1820 \\
\hline Valle de Bravo, Edo.Mex. & 8 & $\begin{array}{l}\text { A209, A210, A503, A505, A506, } \\
\text { A641 }\end{array}$ & $19^{\circ} 14^{\prime} 22^{\prime}$ & $100^{\circ} 05^{\prime} 48^{\prime \prime}$ & 2242 \\
\hline Villa Guerrero, Edo.Mex. & 1 & A216 & $18^{\circ} 57^{\prime} 36^{\prime \prime}$ & $99^{\circ} 38^{\prime} 24^{\prime \prime}$ & 2160 \\
\hline Chilchota, Mich. & 5 & A369, A371, A678, A679 & $19^{\circ} 50^{\prime} 44^{\prime \prime}$ & $102^{\circ} 07^{\prime} 12^{\prime}$ & 1780 \\
\hline Peribán, Mich. & 1 & A 625 & $19^{\circ} 31^{\prime} 01^{\prime \prime}$ & $102^{\circ} 24^{\prime} 51^{\prime \prime}$ & 1640 \\
\hline Queréndaro, Mich. & 13 & $\begin{array}{l}\text { В03, B06, B08, B051, B052,B054, } \\
\text { B055, B056, B057(2), B058, В059 }\end{array}$ & $19^{\circ} 48^{\prime} 33^{\prime \prime}$ & $100^{\circ} 53 ’ 38^{\prime \prime}$ & 1860 \\
\hline $\begin{array}{l}\text { San Angel Zurumucapio, } \\
\text { Mich. }\end{array}$ & 2 & B133 & $19^{\circ} 24^{\prime} 58^{\prime \prime}$ & $102^{\circ} 07^{\prime} 42^{\prime \prime}$ & 1880 \\
\hline Tacámbaro, Mich. & 1 & B81 & $19^{\circ} 14^{\prime} 37^{\prime \prime}$ & $101^{\circ} 28^{\prime} 41^{\prime \prime}$ & 1600 \\
\hline Tancítaro, Mich. & 1 & B41 & $19^{\circ} 25^{\prime} 34^{\prime \prime}$ & $102^{\circ} 17^{\prime} 57^{\prime \prime}$ & 1480 \\
\hline Tingambato, Mich. & 6 & $\begin{array}{l}\text { B137, B139, A484, A485, A486, } \\
\text { A487, A } 680\end{array}$ & $19^{\circ} 30^{\prime} 05^{\prime \prime}$ & $101^{\circ} 51^{\prime} 08^{\prime \prime}$ & 1980 \\
\hline Tzinzunzan, Mich. & 4 & $\mathrm{~B} 80, \mathrm{~B} 100, \mathrm{~B} 130, \mathrm{~B} 132$ & $19^{\circ} 37^{\prime} 40^{\prime \prime}$ & $101^{\circ} 34^{\prime} 43^{\prime \prime}$ & 2050 \\
\hline
\end{tabular}


Cuadro 1. Continúa

\begin{tabular}{|c|c|c|c|c|c|}
\hline Localidad y Estado & $\begin{array}{c}\text { Núm. } \\
\text { de } \\
\text { árboles }\end{array}$ & Clave de identificación & Latitud $N$ & Longitud $O$ & $\begin{array}{l}\text { Altitud } m \\
\text { snm }\end{array}$ \\
\hline Uruapan, Mich. & 20 & $\begin{array}{l}\text { A14TTC, ATGB, B09, B24, B27, } \\
\text { B30, B32, B33, B34, B35, B36, B37, } \\
\text { B44(2), B46(2), B101, B104, B105, } \\
\text { A681 }\end{array}$ & $19^{\circ} 25^{\prime} 34^{\prime \prime}$ & $102^{\circ} 03 ' 41 "$ & 1620 \\
\hline Zinapécuaro, Mich. & 6 & $\mathrm{~B} 60, \mathrm{~B} 63(2), \mathrm{B} 64(2), \mathrm{B} 65$ & $19^{\circ} 50^{\prime} 16^{\prime \prime}$ & $100^{\circ} 49^{\prime} 03^{\prime \prime}$ & 1816 \\
\hline Ziracuaretiro, Mich. & 4 & B01, B107, B108, A582 & $19^{\circ} 25^{\prime} 00^{\prime \prime}$ & $101^{\circ} 54^{\prime} 40^{\prime \prime}$ & 1380 \\
\hline Zitácuaro, Mich. & 24 & $\begin{array}{l}\text { B84, B85, B87, B109(2), B110,B111, } \\
\text { B113, B115, B118, B119, B120, } \\
\text { B121, A206, A491, A492, A493, } \\
\text { A494, A495, A496, A497, A498, } \\
\text { A499, A } 500\end{array}$ & $19^{\circ} 26^{\prime} 54^{\prime \prime}$ & $100^{\circ} 23^{\prime} 26^{\prime \prime}$ & 200 \\
\hline Ocuituco, Mor. & 2 & A517, A518 & $18^{\circ} 52^{\prime} 22^{\prime \prime}$ & $98^{\circ} 46^{\prime} 24^{\prime \prime}$ & 1900 \\
\hline Tetela del Volcán, Mor. & 4 & A516(2), A648, B125 & $18^{\circ} 53^{\prime} 31^{\prime \prime}$ & $98^{\circ} 43^{\prime} 46^{\prime \prime}$ & 2200 \\
\hline Aramberri, N.L. & 5 & B20, B21, A632, A634, A635 & $24^{\circ} 05^{\prime} 58^{\prime \prime}$ & $99^{\circ} 49^{\prime} 02^{\prime \prime}$ & 1100 \\
\hline Achiutla, Oax. & 1 & A 458 & $17^{\circ} 18^{\prime} 16^{\prime \prime}$ & $97^{\circ} 29^{\prime} 18^{\prime \prime}$ & 1940 \\
\hline Ocotlán, Oax. & 1 & A551 & $16^{\circ} 47^{\prime} 30^{\prime \prime}$ & $96^{\circ} 40^{\prime} 31^{\prime \prime}$ & 1500 \\
\hline San Pablo Etla, Oax. & 10 & $\begin{array}{l}\text { A245, A246, A247, A463(2), A550, } \\
\text { A651, A652, A683, A684 }\end{array}$ & $17^{\circ} 08^{\prime} 40^{\prime}$ & $96^{\circ} 45^{\prime} 36^{\prime \prime}$ & 1630 \\
\hline Teposcolula, Oax. & 2 & A459, A649 & 17³3’02”' & $97^{\circ} 25^{\prime} 30^{\prime \prime}$ & 2320 \\
\hline Ahuacatlán, Pue. & 2 & A319, A320 & $20^{\circ} 00^{\prime} 20^{\prime \prime}$ & $97^{\circ} 51^{\prime} 36^{\prime \prime}$ & 1300 \\
\hline Atlixco, Pue. & 3 & A533, A534, A535 & $18^{\circ} 54^{\prime} 25^{\prime \prime}$ & $98^{\circ} 26^{\prime} 15^{\prime \prime}$ & 1840 \\
\hline Huauchinango, Pue. & 5 & A305, A306, A308, A309, A311 & $20^{\circ} 10^{\prime} 00^{\prime \prime}$ & $98^{\circ} 02^{\prime} 00^{\prime}$ & 1472 \\
\hline Puebla, Pue. & 1 & A588 & $19^{\circ} 02^{\prime} 36^{\prime \prime}$ & $98^{\circ} 11^{\prime} 50^{\prime \prime}$ & 2135 \\
\hline San Vicente Coyotepec, Pue. & 3 & A542, A543, A544 & $18^{\circ} 24^{\prime} 14^{\prime \prime}$ & $97^{\circ} 49^{\prime} 52^{\prime \prime}$ & 1900 \\
\hline Tepexi San Vicente, Pue. & 6 & $\begin{array}{l}\text { A536, A537, A538, A539, A540, } \\
\text { A541 }\end{array}$ & $18^{\circ} 34^{\prime} 39^{\prime \prime}$ & $97^{\circ} 55^{\prime} 34^{\prime \prime}$ & 1700 \\
\hline Totoltepec, Pue. & 2 & A546, A547 & $18^{\circ} 13^{\prime} 17^{\prime \prime}$ & $97^{\circ} 51^{\prime} 19^{\prime \prime}$ & 1380 \\
\hline Zacapoaxtla, Pue. & 3 & $\mathrm{~A} 321, \mathrm{~A} 322, \mathrm{~A} 323$ & $19^{\circ} 54^{\prime} 07^{\prime \prime}$ & $97^{\circ} 35^{\prime} 37^{\prime \prime}$ & 1620 \\
\hline Zacatlán Pue. & 6 & $\begin{array}{l}\text { A313, A314, A315, A324, A325, } \\
\text { A326 }\end{array}$ & $19^{\circ} 54^{\prime} 23^{\prime \prime}$ & $97^{\circ} 56^{\prime} 29^{\prime \prime}$ & 1960 \\
\hline Tolimán, Qro. & 1 & B70, B71 & $20^{\circ} 51^{\prime} 29^{\prime \prime}$ & $99^{\circ} 53^{\prime} 55^{\prime \prime}$ & 1660 \\
\hline San Juan del Río, Qro. & 3 & B67, B68, B69 & $20^{\circ} 23^{\prime} 16^{\prime \prime}$ & $100^{\circ} 00^{\prime} 00^{\prime}$ & 1920 \\
\hline San Vicente Tacubaya, S.L.P. & 2 & $\mathrm{C} 285(2)$ & $21^{\circ} 43^{\prime} 03^{\prime \prime}$ & $98^{\circ} 35^{\prime} 14^{\prime \prime}$ & 40 \\
\hline Tamazunchale, S.L.P. & 3 & $\mathrm{~A} 271, \mathrm{C} 277(2)$ & $21^{\circ} 15^{\prime} 40^{\prime \prime}$ & $98^{\circ} 47^{\prime} 30^{\prime \prime}$ & 140 \\
\hline Jaumave, Tamps. & 9 & C295, C296, C423(4), C630(2), A630 & $23^{\circ} 24^{\prime} 19^{\prime \prime}$ & $99^{\circ} 22^{\prime} 49^{\prime \prime}$ & 760 \\
\hline Llera, Tamps. & 2 & $\mathrm{C} 422(2)$ & $23^{\circ} 19^{\prime} 04^{\prime \prime}$ & $99^{\circ} 01^{\prime} 27^{\prime \prime}$ & 280 \\
\hline
\end{tabular}


Cuadro 1. Continúa

\begin{tabular}{lcccc}
\hline Localidad y Estado & $\begin{array}{c}\text { Núm. } \\
\text { de } \\
\text { árboles }\end{array}$ & Clave de identificación & $\begin{array}{c}\text { Latitud N } \\
\text { Longitud O }\end{array}$ & $\begin{array}{c}\text { Altitud m } \\
\text { snm }\end{array}$ \\
\hline Mante, Tamps. & 8 & C291(3), C292, C293(4) & $22^{\circ} 44^{\prime} 36^{\prime \prime}$ & $98^{\circ} 58^{\prime} 17^{\prime \prime}$ \\
Altotonga, Ver. & 8 & $\begin{array}{c}\text { A329, A331, A332, A333, A334, } \\
\text { A335, A336, A337 }\end{array}$ & $19^{\circ} 45^{\prime} 47^{\prime \prime}$ & $97^{\circ} 14^{\prime} 38^{\prime \prime}$ \\
\end{tabular}

${ }^{1}$ Los números clave de las accesiones se cambian periódicamente en los bancos de germoplasma para proteger los materiales propiedad del INIFAP.

coincidieran con los de la biblioteca. Se verificó la pureza de cada pico con el software MSD chemStation. Se calcularon los tiempos de retención promedio crudos y los relativos al tetradecano.

Para cuantificar se ajustó el área del estándar interno de cada muestra a $1 \mathrm{mg}$ y se calculó la concentración de cada pico, dando a su área el valor equivalente a la del estándar interno.

Cálculo de indices Kovats. Se emplearon 2 series de alcanos puros (Sigma Aldrich) C8-C20 y C21-C40, se inyecto $1.5 \mu \mathrm{l}$ de la solución standar, en un Cromatógrafo de Gases Agilent 6890 acoplado a un espectrómetro de masas Agilent 5973 (CG-MS), empleando las condiciones mencionadas anteriormente. El cálculo experimental se realizó mediante la siguiente fórmula:

$$
\text { Índice Kovats }=\left(\frac{\text { TRcompuesto }-\mathrm{TR} n}{\operatorname{TR} N-\mathrm{TRn}}\right) *(100 * \mathrm{z})+(100 * \mathrm{n})
$$

$\mathrm{TRn}=$ tiempo de retención del hidrocarburo eluído antes del compuesto desconocido; TRN= tiempo de retención del hidrocarburo eluído después del compuesto desconocido; $\mathrm{n}=$ número de carbonos del compuesto eluido antes que el compuesto desconocido, $\mathrm{z}=$ diferencia del número de átomos de carbono del hidrocarburo eluido después del compuesto desconocido, menos el hidrocarburo eluido antes del compuesto desconocido.

Análisis estadístico. Se realizó una matriz de concentración de los compuestos químicos identificados (mg del compuesto/g de hoja seca). Se tomaron en cuenta sólo los compuestos químicos puros y con proporción mayor a $1 \%$. También se realizó una matriz de proporciones que expresa la concentración del compuesto químico en relación con la concentración total de todos los compuestos presentes en cada accesión. Se realizó la estandarización de la matriz con la formula: $\Sigma$ (valor del compuesto $i$ en una accesión - promedio del compuesto $i$ en toda la muestra; $i=1$ /desviación estándar del compuesto $i$ en toda la muestra) (Penrose, 1953), para eliminar la varianza entre los compuestos químicos.
Para la caracterización química de los árboles de aguacate criollo se empleó un análisis de cúmulos (matriz de distancias Manhattan y algoritmo UPGMA [promedio no ponderado de pares de grupos]) y un análisis de discriminantes, para determinar las características químicas diferentes entre los grupos encontrados. También se usó la correlación de Spearman con corrección de Bonferroni para determinar la relación entre la localidad geográfica de los árboles y los grupos químicos encontrados. Se realizó un análisis no paramétrico debido a que los datos de altitud y latitud no tenían distribución normal.

\section{Resultados}

Se encontraron 64 compuestos químicos en la fracción volátil de las hojas jóvenes de aguacate criollo mexicano, de los que fueron identificados 41 , incluyendo todos los mayoritarios: 1 ácido graso, 12 alcanos, 2 aldehídos, 2 diterpenos, 2 fenil propanoides, 9 monoterpenoides, 11 sesquiterpenoides, 1 sesterpeno y 1 triterpeno (Rincón-Hernández, 2005; Cuadro 2). La clasificación química es la siguiente:

Ácido graso: ácido mirístico. Alcanos: hexadecano, octadecano, nonadecano, heneicosano, eicosano, docosano, tricosano, tetracosano, pentacosano, heptacosano, octacosano, dotriacontano. Aldehídos: 2-hexenal, 3-metoxicinamaldehido. Diterpeno: fitol y fitan. Fenil propanoides: eugenol metil éter, estragol. Monoterpenoides: $\alpha$-pineno, $\alpha$-terpineno, $\beta$-pineno, sabineno, limoneno, eucaliptol, cis- $\beta$-ocimeno, $Z, \beta$-terpineol, linalool. Sesquiterpenoides: $\alpha$-cubebeno, $\beta$-cariofileno, Cis, cis, cis-4, 7, 10 -cicloundecatrieno, $1,1,4,8$ tetrametil, $\quad$ D-germacreno, $\gamma$-cadineno, nerolidol, $\beta$-nerolidol, 1-hidroxi-1,7-dimetil-4-isopropil2,7-ciclodecadieno, D-nerolidol, óxido de cariofileno, $\beta$-bis-,benceno, 1,1'-(1,2-ciclobutanodil). $\quad$ Sesterterpeno: 2,6,10,14,18-pentametil-2,6,10,14,18-eicosapenteno. Triterpeno: escualeno; y 23 compuestos no identificados, 
Cuadro 2. Compuestos químicos foliares identificados en árboles de P. americana var. drymifolia. Índices Kovats obtenidos con las series de alcanos C8-C40

\begin{tabular}{|c|c|c|c|}
\hline $\begin{array}{l}\text { Número del } \\
\text { compuesto químico }\end{array}$ & $\begin{array}{l}\text { Nombre del compuesto químico o masa molecular del } \\
\text { compuesto químico no identificado }\end{array}$ & $\begin{array}{l}\text { Tiempo de } \\
\text { retención promedio } \\
\text { (min) }\end{array}$ & Índice Kovat (I) \\
\hline 1 & 2-hexenal & 3.35 & 990 \\
\hline 2 & $\alpha$-pineno & 3.94 & 1069 \\
\hline 3 & $\alpha$-terpineno & 4.23 & 1108 \\
\hline 4 & $\beta$-pineno & 4.26 & 1112 \\
\hline 5 & Sabineno & 4.34 & 1123 \\
\hline 6 & Limoneno & 4.65 & 1164 \\
\hline 7 & Eucaliptol & 4.68 & 1168 \\
\hline 8 & cis- $\beta$-ocimeno & 4.73 & 1164 \\
\hline 9 & $\mathrm{Z}, \beta$-terpineol & 5.01 & 1217 \\
\hline 10 & Linalool & 5.13 & 1240 \\
\hline 11 & Estragol & 5.93 & 1356 \\
\hline 12 & $\alpha$-cubebeno & 7 & 1508 \\
\hline 13 & Eugenol metil éter & 7.28 & 1554 \\
\hline 14 & $\beta$-cariofileno & 7.52 & 1593 \\
\hline 15 & Cis, cis, cis-4,7,10-cicloundecatrieno, 1,1,4,8-tetrametil & 7.74 & 1631 \\
\hline 16 & D-germacreno & 7.91 & 1659 \\
\hline 17 & Nerolidol & 8.1 & 1692 \\
\hline 18 & $\gamma$-cadineno & 8.11 & 1693 \\
\hline 19 & $\beta$-nerolidol & 8.29 & 1724 \\
\hline 20 & Hexadecano & 8.41 & 1745 \\
\hline 21 & 3-Metoxicinamaldehido & 8.43 & 1748 \\
\hline 22 & 1-hidroxi-1,7-dimetil-4-isopropil-2,7-ciclodecadieno & 8.49 & 1759 \\
\hline 23 & D-nerolidol & 8.52 & 1764 \\
\hline 24 & Óxido de cariofileno & 8.59 & 1776 \\
\hline 25 & Ácido mirístico, metil, éster & 9.19 & 1878 \\
\hline 26 & $\beta$-bis-,benzeno,1,1' -(1,2-ciclobutanodil) & 9.58 & 1945 \\
\hline 27 & Heptadecano & 9.7 & 1966 \\
\hline 28 & Nonadecano & 10.24 & 2044 \\
\hline 29 & Fitan & 11.28 & 2207 \\
\hline 30 & Fitol & 11.53 & 2254 \\
\hline 31 & Heneicosano & 11.97 & 2335 \\
\hline 32 & Eicosano & 12.08 & 2356 \\
\hline 33 & Docosano & 12.46 & 2427 \\
\hline 34 & Tricosano & 12.53 & 2440 \\
\hline 35 & Tetracosano & 12.96 & 2524 \\
\hline
\end{tabular}


Cuadro 2. Continúa

\begin{tabular}{cccc}
\hline $\begin{array}{c}\text { Número del } \\
\text { compuesto químico }\end{array}$ & $\begin{array}{c}\text { Nombre del compuesto químico o masa molecular del } \\
\text { compuesto químico no identificado }\end{array}$ & $\begin{array}{c}\text { Tiempo de } \\
\text { retención promedio } \\
\text { (min) }\end{array}$ & $\begin{array}{c}\text { Índice Kovat (I) } \\
36\end{array}$ \\
\hline 37 & Pentacosano & 12.98 \\
38 & Pentacosano & 13.06 & 2528 \\
39 & Heptacosano & 14.46 & 2544 \\
40 & Octacosano & 14.52 & 2840 \\
& Escualeno & 15.35 & 3005 \\
\hline
\end{tabular}

generalmente con menos del 1\% de cada muestra (RincónHernández, 2005).

Caracterización química foliar de los árboles de los bancos de germoplasma INIFAP Michoacán. Se encontraron 2 grandes grupos químicos (Fig. 1). El grupo A que contiene el $17.5 \%$ de la muestra y está integrado por varios subgrupos el A1, A2 y A3 que representan el 4.4\%, 7.9\% y $5.2 \%$ respectivamente, y son diferentes entre sí en un $60 \%$. El grupo B representa el $82.5 \%$ de la muestra; está integrado por 2 subgrupos, el B1 y el B2, que representan el $18.2 \%$ y el $64.3 \%$ respectivamente, y son diferentes entre sí en un 40\%. El subgrupo B1 lo integran los subgrupos B1-1 y B1-2 que contienen el 9.5\% y 8.7\% respectivamente, y son diferentes entre si en un 25\%. El subgrupo B2 está integrado por los subgrupos B2-1 y el B2-2, los cuales representan un $37.7 \%$ y $26.6 \%$ respectivamente, y son diferentes entre sí en un 18\%. A una escala de $10 \%$ de disimilitud se encontraron 22 grupos químicos en toda la muestra.

Caracterización química de los grupos. De acuerdo con el análisis de discriminantes (Cuadro 3), los compuestos químicos representativos entre los grupos A y $\mathrm{B}$ son el pentacosano, $\alpha$-cubebeno, heptacosano, ácido miristico metil éter, $\beta$-bis-,benceno,1,1'-(1,2-ciclobutanedil), $\beta$-cariofileno, $\beta$-pineno y principalmente el estragol, que en el grupo A es del 10\% y en el grupo B 65\%. La diferencia más notable entre los grupos $\mathrm{B} 2$ es el estragol, con $86 \%$ de concentración promedio para B2-1-1 y 75\% para B2-1-2. El $\alpha$-pineno, $\beta$-pineno y $\beta$-cariofileno presentan al menos el doble de concentración en el grupo B2-1-2 que en el B2-1-1. (Cuadro 4).

Clasificación química de los híbridos previamente caracterizados. En el grupo A se encuentran dos híbridos, Persea americana var. drymifolia x P.shiedeana y el P. americana var. drymifolia x $P$. americana var. americana (accesiones A271 y A582) en el subgrupo A2, subgrupo A2-2 y en el subgrupo A3, subgrupo A3-2, respectivamente (Figura 2). El híbrido colectado $P$. americana var. drymifolia x $P$. ame- ricana var. guatemalensis (accesión A541), previamente caracterizado morfológicamente (Sánchez-Pérez, 1999), se encuentra en el subgrupo B1, en el subgrupo B1-2-3 (Fig. 3).

La principal diferencia química entre los grupos es la concentración promedio del fenilpropanide estragol: en el grupo A es de 10\% mientras que en el B es de $65 \%$; en el subgrupo B1, donde se encuentra el híbrido de $P$. americana var. drymifolia x P. americana var. guatemalesis, la concentración del estragol es de 35\%; y en el subgrupo B2, donde no se encontró ningún híbrido, la concentración es del 73\%. (Fig. 4).

El grupo B2 tiene 2 subgrupos a una escala de disimilitud del 10\%; B2-1 y B2-2, los cuales se diferencian principalmente por 11 compuestos químicos (Figs. 5a y 5b). El compuesto más representativo es el estragol (no incluido en la figura) con una concentración promedio del $80 \%$ en B2-1 y $64 \%$ en B2-2. Se incluye un cromatograma de la accesión 305, representativo del grupo químico B2 (Fig. 6).

Localización geográfica de los grupos. Se realizó una comparación de Mann-Whitney entre los 2 grupos quími$\cos (\mathrm{A}$ y B $)$ con respecto al lugar de procedencia (altitud, latitud y longitud) de los árboles de P. americana var. drymifolia (Cuadro 5). Se encontró que existe diferencia entre la altitud de origen de las accesiones; las localidades de origen del grupo A se encuentran entre 1250 y 1800 m snm y las del grupo B entre los 1500 y $1800 \mathrm{~m}$ snm. No hubo diferencias significativas entre los grupos atribuibles a la latitud o a la longitud.

En cuanto a la distribución geográfica de árboles típicos de Persea americana var. drymifolia (grupo B2), el origen de los árboles en el B2-1 se distribuye primordialmente en estados del centro de México al igual que el origen de la mayoría de los árboles en el grupo B2.2. La mayoría de las variantes químicas $P$. americana var. drymifolia coinciden en las mismas regiones, excepto las del grupo B2.2 que también se encuentran en los estados 
Cuadro 3. Análisis de discriminantes entre los grupos A y B con los compuestos foliares de los árboles de P. americana var. drymifolia, con 13 variables incluidas en el modelo. Lambda de Wilks: 0.34 aprox. F $(13,238)=34.888 \mathrm{p}<0.0000$

\begin{tabular}{|c|c|c|c|c|c|c|}
\hline & $\begin{array}{c}\text { Lambda de } \\
\text { Wilks }\end{array}$ & $\begin{array}{l}\text { Lambda } \\
\text { parcial }\end{array}$ & $F_{(1,238)}$ & $p$ & Tolerancia & Tolerancia $-R^{2}$ \\
\hline Pentacosano & 0.36 & 0.95 & 12.36 & $* * *$ & 0.81 & 0.19 \\
\hline$\alpha$-cubebeno & 0.35 & 0.98 & 5.86 & $* *$ & 0.86 & 0.14 \\
\hline Octacosano & 0.36 & 0.96 & 11.87 & $* * *$ & 0.82 & 0.18 \\
\hline $\begin{array}{l}\text { Ácido miristico, metil, } \\
\text { ester }\end{array}$ & 0.36 & 0.96 & 8.98 & $* * *$ & 0.84 & 0.16 \\
\hline $\begin{array}{c}\beta \text {-bis-, benceno, } \\
\left.1,1^{\prime} \text {-(1,2-ciclobutanedil }\right)\end{array}$ & 0.37 & 0.93 & 16.98 & $* * * *$ & 0.27 & 0.73 \\
\hline$\beta$-cariofileno & 0.36 & 0.97 & 7.95 & $* *$ & 0.75 & 0.25 \\
\hline$\alpha$-pineno & 0.35 & 0.97 & 7.47 & $* *$ & 0.25 & 0.75 \\
\hline Estragol & 0.50 & 0.67 & 119.71 & $* * * *$ & 0.65 & 0.35 \\
\hline
\end{tabular}

$* \mathrm{p}<0.05, * * \mathrm{p}<0.01, * * * \mathrm{p}<0.001, \mathrm{y} * * * * \mathrm{p}<0.0001$

Cuadro 4. Abundancia entre los compuestos químicos foliares de los subgrupos de B2. Picos cromatográficos obtenidos mediante CG-MS

\begin{tabular}{|c|c|c|c|c|}
\hline Nombre del compuesto químico & $\begin{array}{l}\text { Porcentaje } \\
\text { promedio } \\
\text { B2-1-1 }\end{array}$ & $\begin{array}{c}\text { Error estándar } \\
(+/-)\end{array}$ & $\begin{array}{c}\text { Porcentaje } \\
\text { promedio } \\
\text { B2-1-2 }\end{array}$ & $\begin{array}{c}\text { Error estándar } \\
(+/-)\end{array}$ \\
\hline$\alpha$-pineno & 0.862 & 0.013 & 1.503 & 0.022 \\
\hline$\beta$-pineno & 1.280 & 0.022 & 1.845 & 0.024 \\
\hline Estragol & 85.609 & 0.069 & 75.088 & 0.216 \\
\hline$\beta$ - cariofileno & 1.415 & 0.024 & 3.098 & 0.174 \\
\hline
\end{tabular}

Cuadro 5. Comparación de Mann-Whitney entre los grupos químicos y la procedencia de los árboles de Persea americana var. drymifolia. Relación entre los grupos químicos obtenidos de la figura 1 (A, B) y el lugar de origen de los árboles colectados en los bancos de germoplasma. Bonferroni $\mathrm{p}<0.025$

\begin{tabular}{|c|c|c|c|c|c|c|c|c|c|}
\hline \multicolumn{10}{|c|}{ Mann-Whitney $U$} \\
\hline & $\begin{array}{l}\text { Rank } \\
\text { Sum A }\end{array}$ & $\begin{array}{c}\text { Rank } \\
\text { Sum B }\end{array}$ & $U$ & $Z$ & Valor de $p$ & $\begin{array}{c}Z \\
\text { ajustada }\end{array}$ & $\begin{array}{c}\text { Valor } \\
\text { de } p\end{array}$ & $n A$ & $n B$ \\
\hline Altitud & 3882 & 26994 & 2936 & -3.441 & 0.001 & -3.445 & 0.001 & 43 & 205 \\
\hline Latitud & 6088.5 & 24787.5 & 3672.5 & 1.719 & 0.086 & 1.719 & 0.086 & 43 & 205 \\
\hline
\end{tabular}


de Nuevo León, Tamaulipas, Norte de Veracruz, Jalisco, Aguascalientes y Oaxaca, en los que no hay variantes del grupo B2-1 (Fig. 7).

\section{Discusión}

Casi todos los compuestos químicos encontrados en las hojas jóvenes de aguacate criollo mexicano (Cuadro 2) ya habían sido registrados, como el $\beta$-cariofileno, $\alpha$-cubebeno, eugenol metil éter, D-germacreno, 2-hexanal, hexadecano, linalool, limoneno, nerolidol, octadecano, $\alpha$-pineno, $\beta$-pineno y, como componente mayoritario, el estragol (Sagrero-Nieves y Bartley; 1995; Scora y Scora, 200; Wu et al., 2007; Bravo-Monzón y Espinosa-García, 2008; Torres-Gurrola et al., 2009). Existe una gran diversidad de compuestos químicos que ya han sido registrados en aguacate, pero no se encontraron en las hojas jóvenes de P. americana var. drymifolia, y un compuesto químico, que sólo se ha encontrado en las hojas jóvenes (Rincón-Hernández y Espinosa-Garcia, 2008); estas diferencias químicas pueden deberse a la ontogenia de las hojas, como en el caso de Umbellularia californica (Goralka et al., 1996); al uso de hojas maduras (Torres-Gurrola et al., 2009); volátiles foliares emitidos por hojas vivas (Bravo-Monzón y Espinosa-García, 2008) o al uso del aceite esencial de uno, o de muestras compuestas de muy pocos individuos de P. americana var. drymifolia (Sagrero-Nieves y Bartley; 1995; Scora y Scora, 2000).

Caracterización química. Se encontró una gran variabilidad química foliar en Persea americana var. drymifolia, en los bancos de germoplasma INIFAP, Michoacán, se analizaron 250 árboles de 14 estados en 52 accesiones. Esto es similar a lo encontrado en hojas maduras de aguacate criollo del banco de germoplasma INIFAP, Celaya, con 291 árboles de 7 estados en 35 accesiones (Torres-Gurrola et al., 2009). Comparando esta clasificación química con la obtenida por Torres-Gurrola et al. (2009), también se observan 2 grupos químicos mayoritarios, cada uno con el $49 \%$ de los árboles. En uno de los grupos, la concentración promedio de estragol es de $18.5 \%$, y en el otro de $69.2 \%$. En los bancos de germoplasma de Michoacán también hay varios grupos similares a los que se acaban de mencionar, pues el grupo B2 que contiene los árboles típicos de la variedad drymifolia tiene el $64 \%$ de los árboles y el resto de los árboles, que posiblemente son híbridos, están en el grupo A y el B1.

Esta variabilidad puede estar asociada a la susceptibilidad o resistencia a plagas y enfermedades, al origen geográfico de los árboles que frecuentemente presentan diferencias en su expresión genética (Rice et al., 1978;
Sturgeon, 1979; Gouyon et al., 1983; Cates y Redak, 1988; Langenheim et al., 1980; Langenheim, 1986; Linhart, 1991; Edwards et al., 1993; Espinosa-García, 2001; Langenheim, 2003), o bien a las cruzas y retrocruzas que posiblemente han ocurrido cuando las variedades han estado en contacto debido a la acción humana directa o indirecta (Galindo-Tovar et al., 2008).

El componente químico mayoritario en los bancos de Michoacán es el estragol, al igual que en el banco de germoplasma de Celaya analizado por Torres-Gurrola et al. (2009). Este fenilpropanoide ha servido para distinguir $P$. americana var. drymifolia de otras variedades y para detectar híbridos. Para la identificación del taxón, el estragol debe representar un $60 \%$ o más del aceite esencial (Scora y Bergh, 1992). Se propone, así, que los árboles que pertenecen al grupo químico A son híbridos con características dominantes a la variedad distinta a la drymifolia, ya que en éstos la proporción del estragol es mucho menor al 60\% (Scora y Bergh, 1992). Se han realizado otros trabajos en los bancos de germoplama INIFAP Michoacán, como el de Cuiris et al. (2009), realizado en el de Uruapan, Michoacán, uno de los incluidos en este estudio, en el que emplearon marcadores moleculares de tipo microsatélites (ISSR). Ellos encontraron 2 grupos, como en el presente trabajo (B1 y B2), y concluyen que existe una gran variabilidad genética dentro de $P$. americana var. drymifolia. Estas aseveraciones coinciden con los datos químicos de este trabajo; lamentablemente no podemos hacer una comparación entre la variabilidad química y genética, debido a que los números de las accesiones se cambian periódica e intencionalmente por el INIFAP para proteger su material. Clasificación química de los hibridos previamente caracterizados. Encontramos que los híbridos se encuentran en grupos diferentes, lo que sugiere que los compuestos químicos foliares encontrados nos ayudaron a diferenciar árboles de $P$. americana var. drymifolia de híbridos.

Ubicación geográfica de los híbridos. Se sabe que las variedades de Persea americana pueden hibridizarse fácilmente entre sí y con P. shiedeana (Mijares-Oviedo y López-López, 1998), y que los terpenos o fenilpropanoides pueden usarse para identificar las variedades y los híbridos (Scora y Bergh, 1992; Wu et al., 2007). Por lo anterior, esperábamos que el análisis de cúmulos ubicara a los híbridos caracterizados por Sánchez-Pérez (1999) en grupos separados de los de la variedad drymifolia, lo que así ocurrió, pues los híbridos A271, A541 y A582 se encuentran en los grupos A y B1. La existencia de híbridos con diferente dominancia de los progenitores fue confirmada por Chen et al. (2009). Por ejemplo, el aguacate Hass es un híbrido con $58 \%$ de su material genético proveniente de la variedad guatemaltensis y $42 \%$ de la variedad drymifolia. La accesión A541, que es el híbrido entre Persea ameri- 


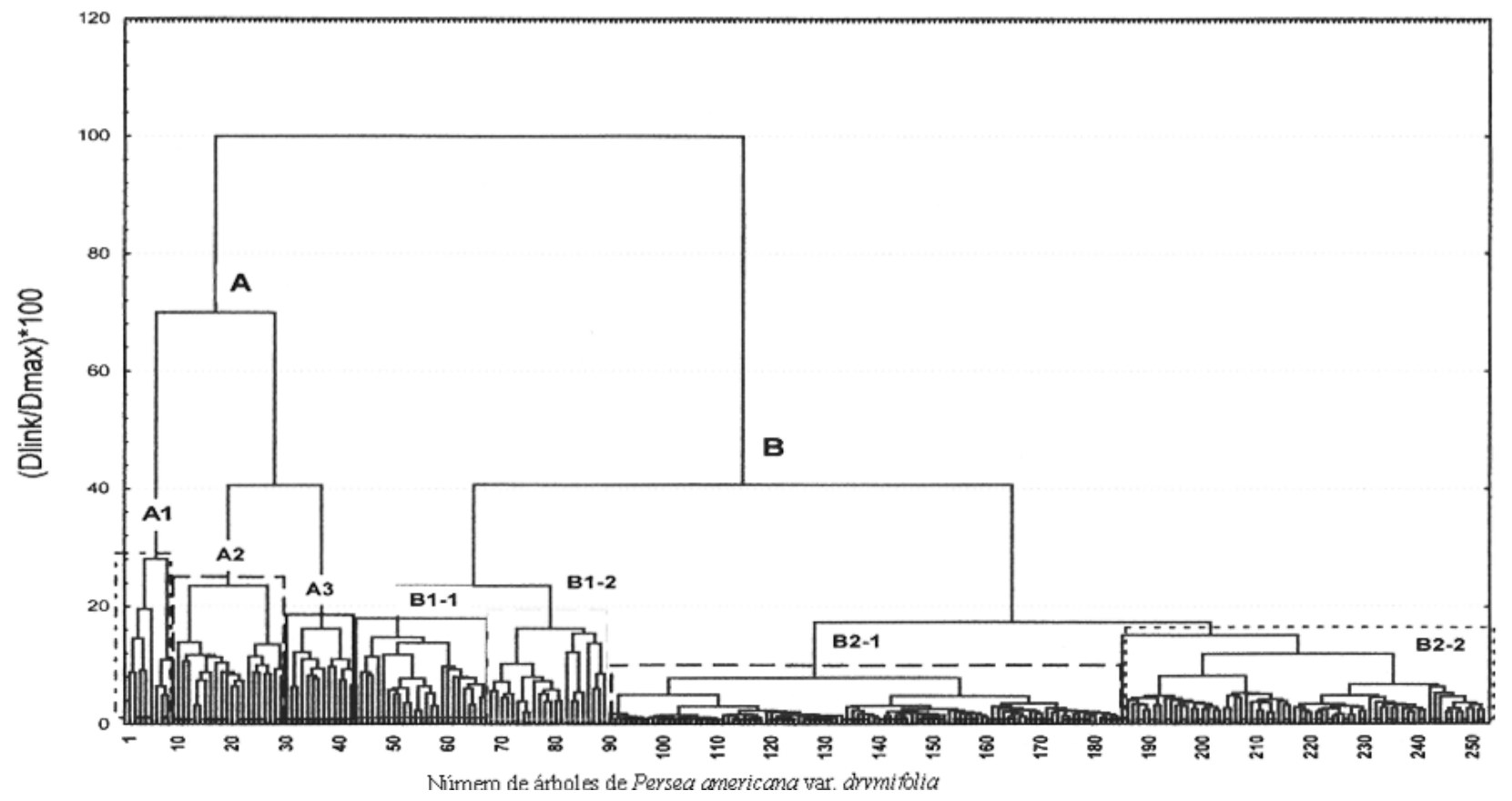

Figura 1. Dendrograma de disimilitud de árboles de Persea americana var. drymifolia de los bancos de germoplasma INIFAP de Uruapan, Cupatitzio y Apatzingán. La matriz de distancia fue calculada con el algoritmo city-block (Manhattan) y el algoritmo UPGMA para formar los grupos. (Dlink/Dmax) * 100 es el porcentaje de disimilitud.

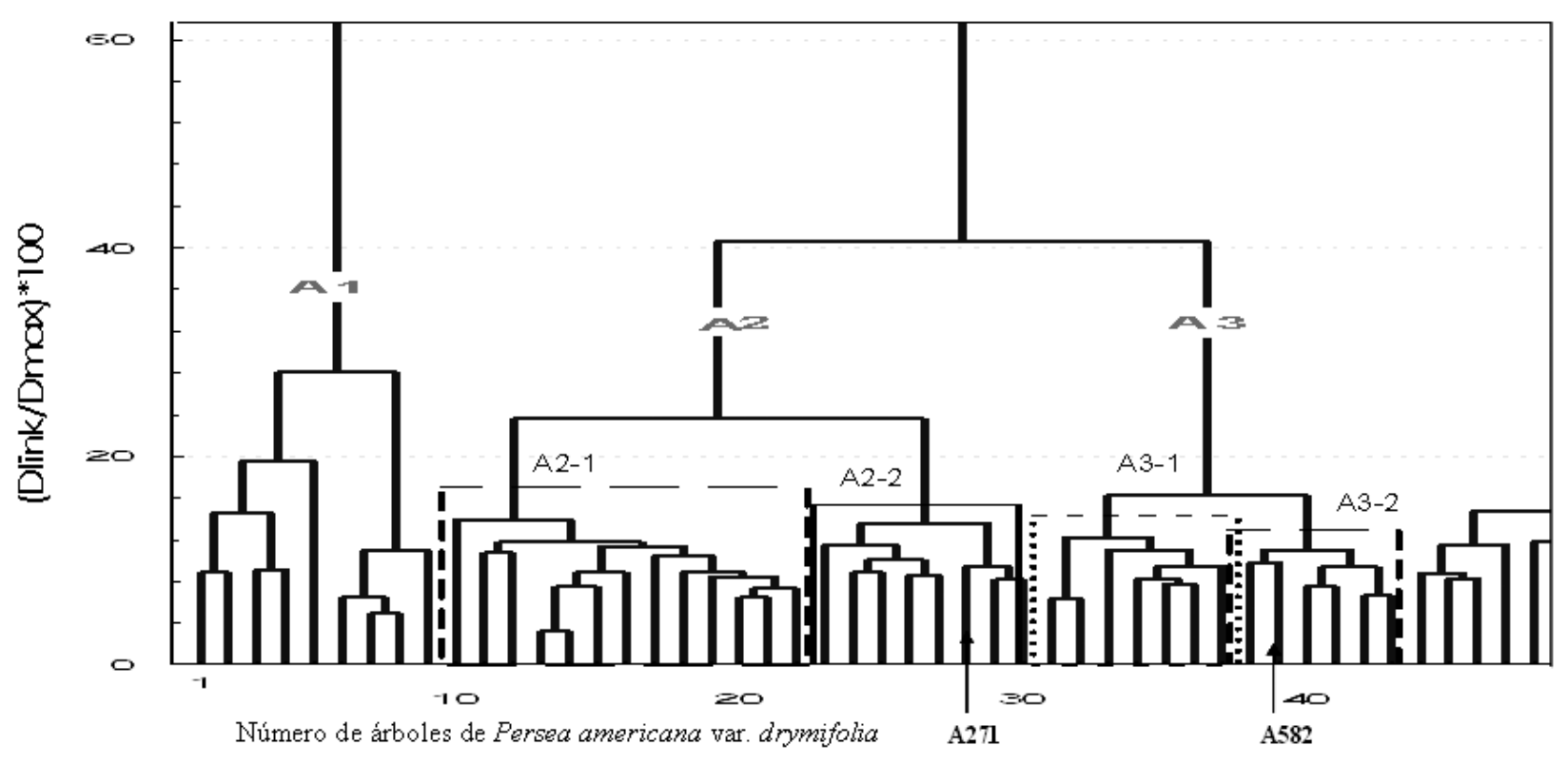

Figura 2. Dendrograma de subgrupos A. Las flechas indican la ubicación de los híbridos de Persea americana var. drymifolia x $P$. americana var. americana y P. americana var. drymifolia x P. shiedeana. 


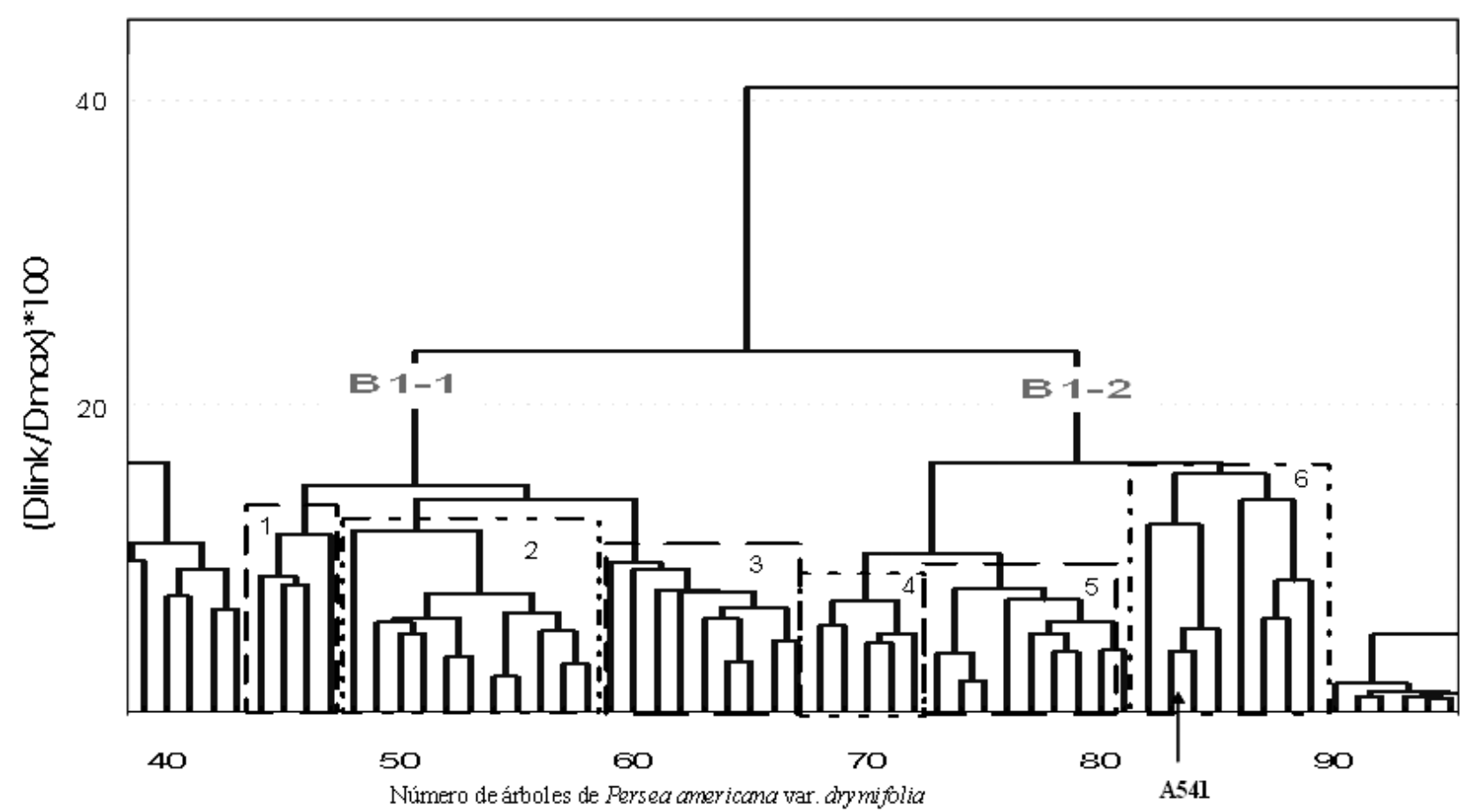

Figura 3. Dendrograma de subgrupos químicos de B1 y el híbrido Persea americana var. drymifolia $\mathrm{x}$ P. americana var. guatemalensis. La flecha indica el híbrido. Donde: subgrupo 1 = B1-1-1, subgrupo 2 = B1-1-2, subgrupo 3= B1-1-3, subgrupo 4= B2-2-1, subgrupo $5=$ B1-2-2, subgrupo $6=$ B1-2-3.

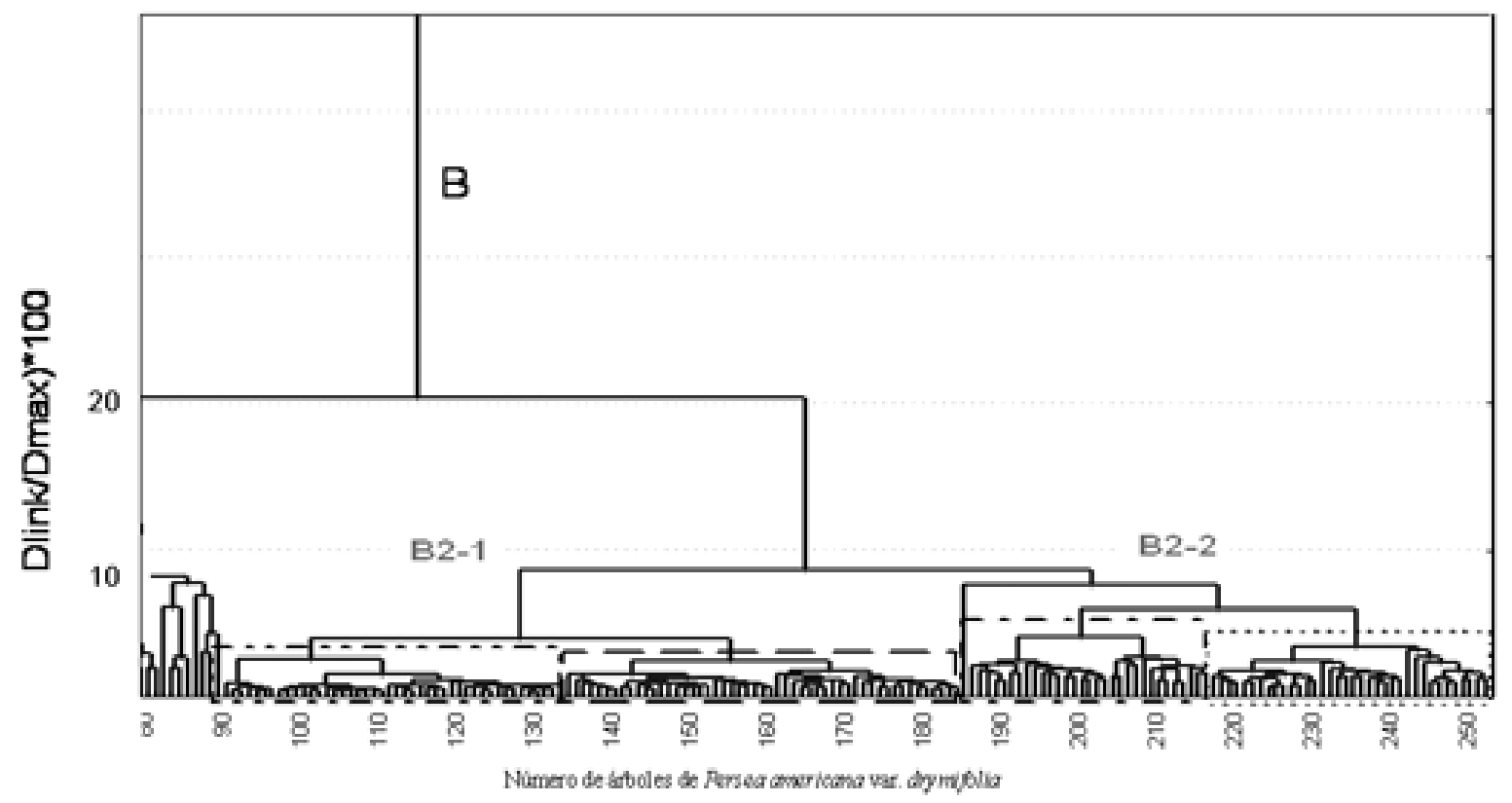

Figura 4. Dendrograma de subgrupos químicos de B2, árboles de Persea americana var. drymifolia. 

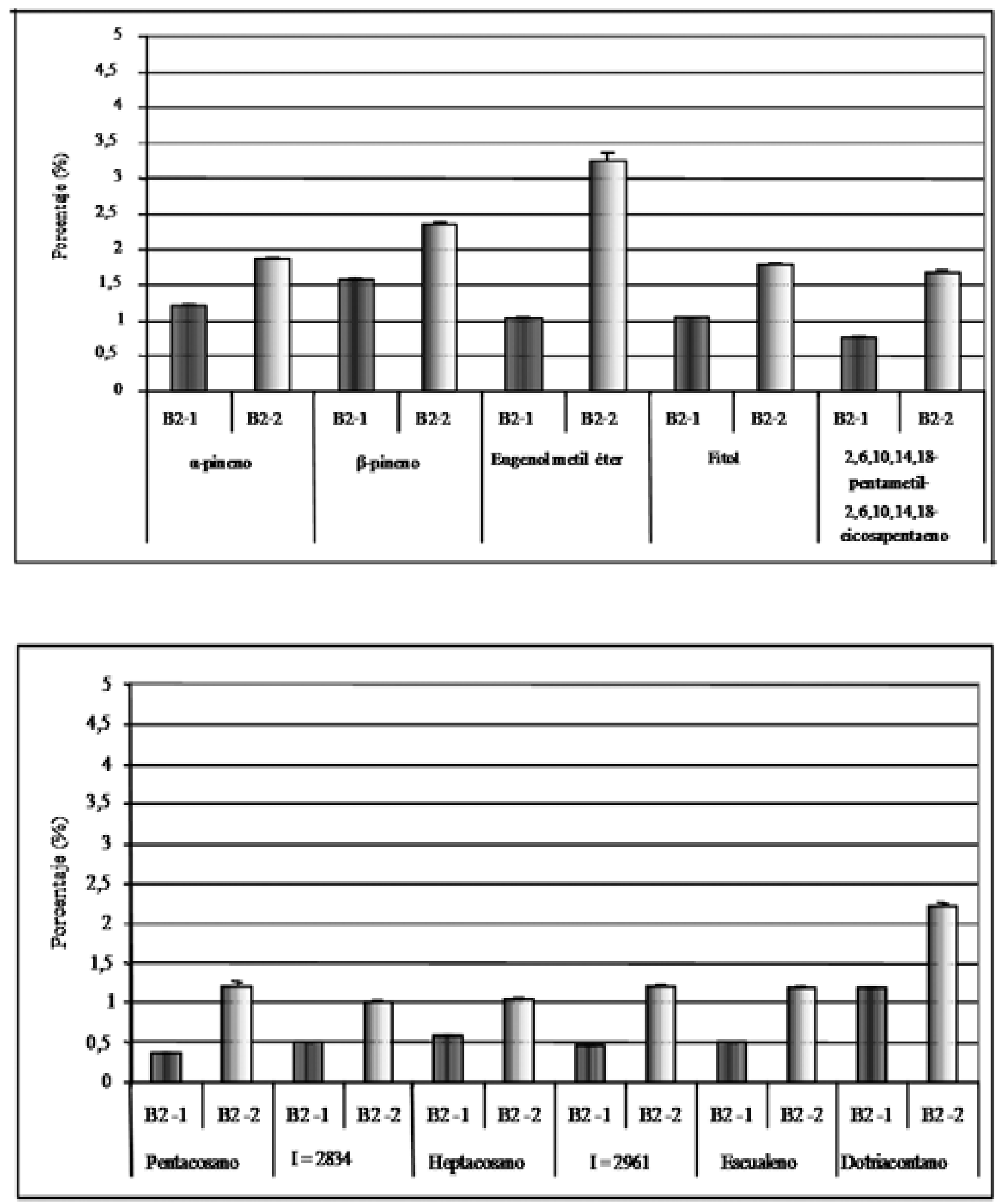

Figura 5. a) diferencias químicas foliares entre los subgrupos de B2.; b) diferencias químicas foliares entre los subgrupos de B2. Donde: I = Índice Kovat. 


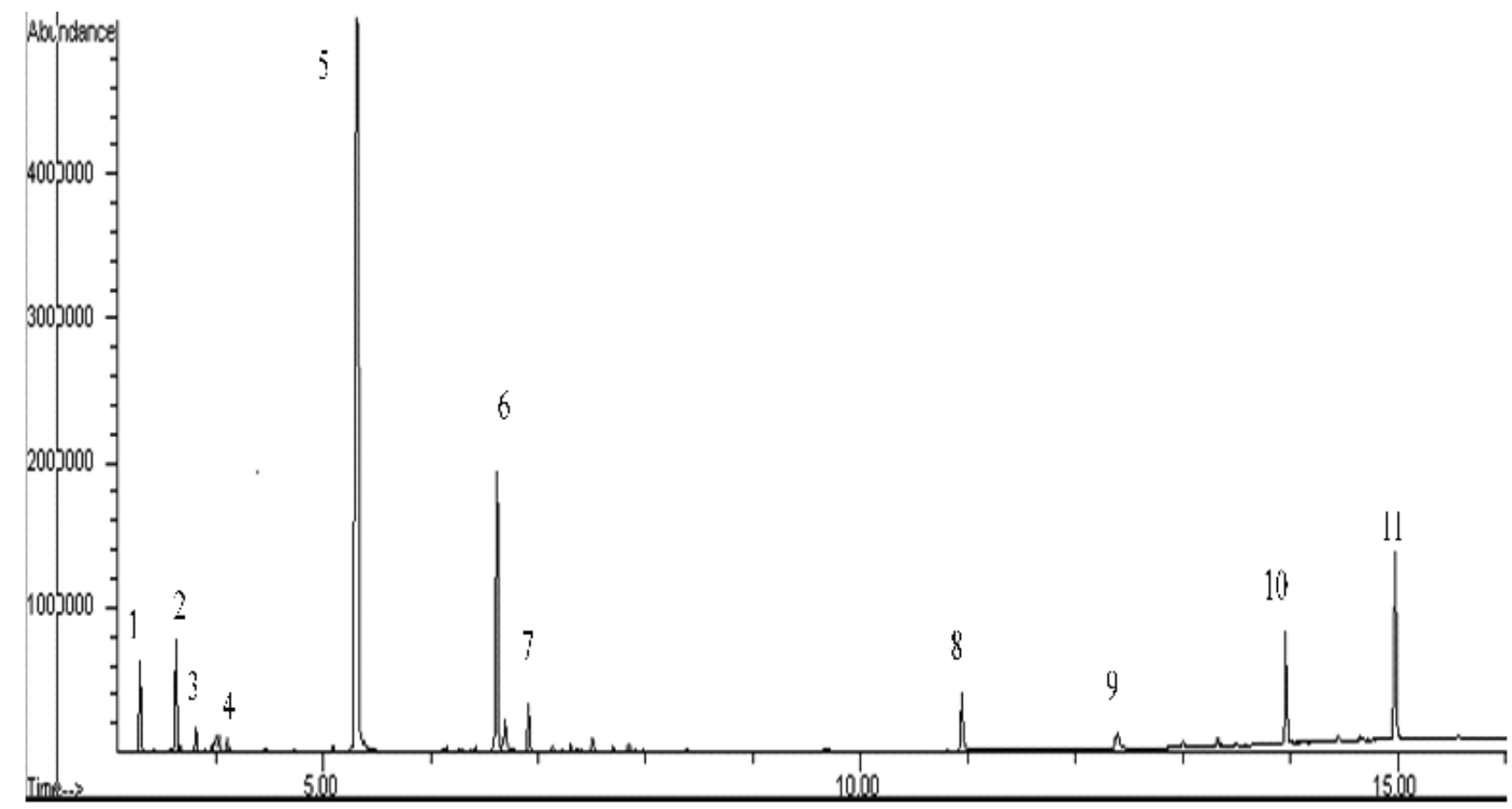

1. 2-hexanal, 2. $\alpha$-pineno, 3. $\beta$-pineno, 4. Sabineno, 5. Estagol, 6. Tetradecano 7. $\beta$-cariofileno, 8. Octadecano, 9. Docosano, 10. Heptacosano, 11. Escualeno.

Figura 6. Cromatograma representativo del grupo químico B2 (accesión 305).

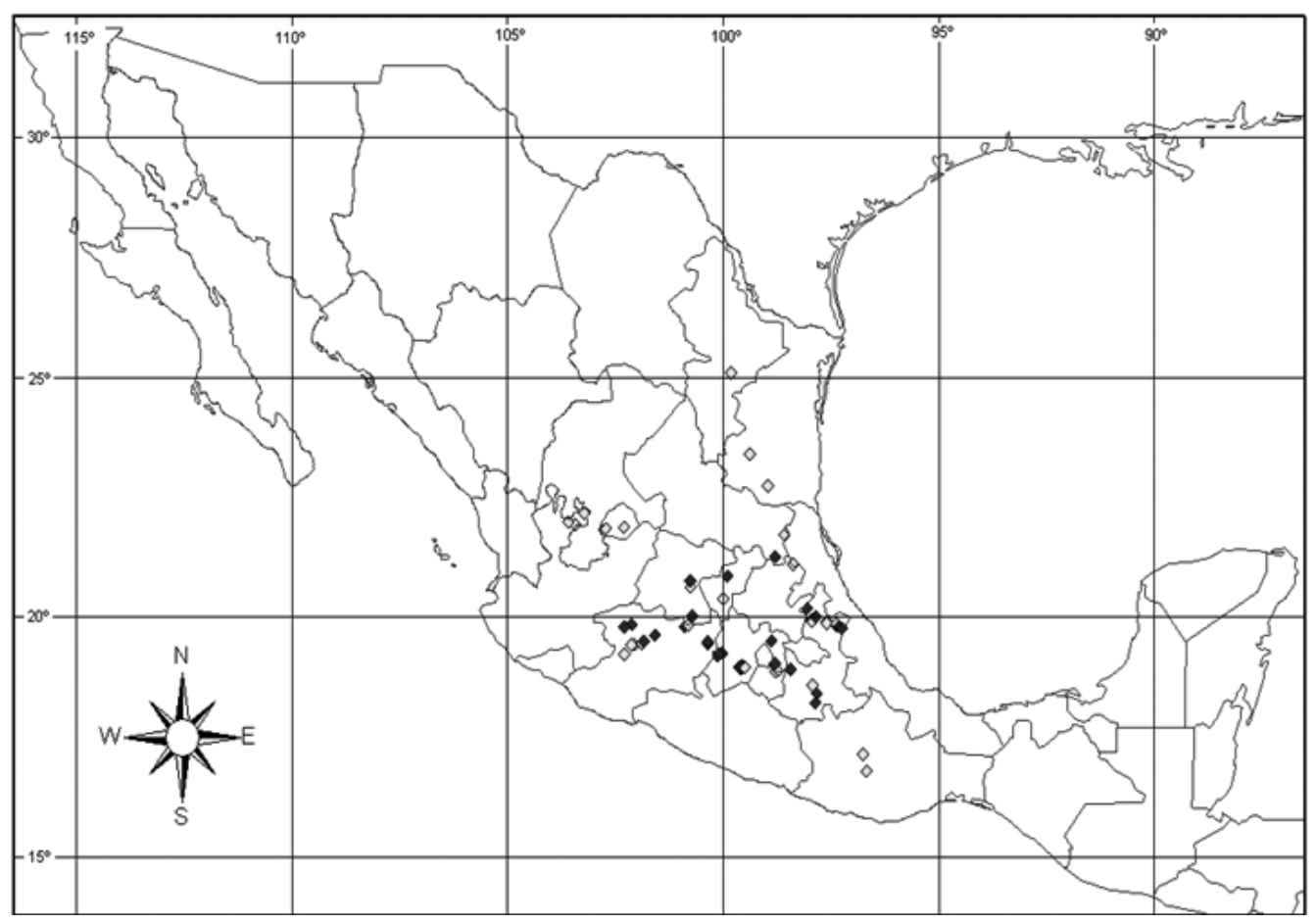

Distribución de grupos

de Criollos

$\diamond B 2-2$

- B2-1

Coordenadas Geografictcas cada $5^{\circ}$

Escala aproximada

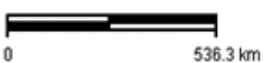

Figura 7. Distribución geográfica de los grupos químicos de aguacate criollo. 
cana var. drymifolia x P. americana var. guatemalensis, estuvo en el grupo B1, donde predominaron las características químicas de la variedad drymifolia. Esto podría explicarse si este híbrido fuera resultado de retrocruzas de un híbrido 50-50, P. americana var. drymifolia x P. americana var. guatemalensis con $P$. americana var. drymifolia, tal como ocurrió con el cultivar Noga, con $71 \%$ de la variedad drymifolia y $29 \%$ de la variedad guatemalensis, o el cultivar Fuerte con $99 \%$ de predominancia de la variedad drymifolia (Chen et al., 2009).

Como en el grupo químico B2 no se encontró ningún híbrido previamente caracterizado, sugerimos que son árboles típicos de Persea americana var. drymifolia. Este tipo de agrupación también ocurrió con los árboles del banco de germoplasma de Celaya; el grupo IIB2 tuvo en promedio $69 \%$ de estragol, mientras que en otros grupos de jerarquía equivalente, la concentración promedio fue de $18.5 \%$ o menor (Torres-Gurrola et al., 2009). Esto sugiere que hay híbridos no detectados en el banco de germoplasma de Celaya. Se sabe que las variedades de aguacate se encuentran a diferentes altitudes: P. americana var. americana a menos de $1000 \mathrm{~m} \mathrm{snm}$. P. americana var. guatemalensis de los 1000 hasta los 2000 y P. americana var. drymifolia de los 1500 a 3000 (Popenoe, 1952), aunque pueden existir algunas excepciones, como el ejemplar tipo de la variedad drymifolia, proveniente de Papantla, Ver., que está ubicada a $180 \mathrm{~m}$ snm. Algunas de estas excepciones pueden deberse a individuos que han sido plantados en este tipo de localidades. Si consideramos que las variedades guatemaltemalensis y americana se desarrollan en elevaciones menores que la variedad drymifolia y que los híbridos se desarrollan en altitudes intermedias a las típicas de los progenitores, entonces la altitud en la que se desarrollan los árboles y su composición química sugiere si son híbridos o no. La altitud de la cual provienen las accesiones del grupo A está entre los 1250 y los 1 $800 \mathrm{~m} \mathrm{snm}$, que representa un intervalo altitudinal menor al del grupo $\mathrm{B}$, que agrupa a los probables árboles de $P$. americana var. drymifolia e híbridos que va de los 1500 a $2000 \mathrm{~m}$ snm Esto hace más fuerte nuestra suposición de que los árboles pertenecientes al grupo A son híbridos con características dominantes de las variedades diferentes a la variedad drymifolia, ya que éstas se encuentran en altitudes menores que la variedad drymifolia, mientras que en el grupo B, los supuestos híbridos con características dominantes de $P$. americana var. drymifolia, se encuentran en una altitud promedio de1 500 a $2000 \mathrm{~m} \mathrm{snm}$.

El fenilpropanoide estragol y los compuesto químicos foliares, se confirmaron como buenos marcadores químicos, ya que permitieron distinguir los híbridos de los árboles típicos de aguacate criollo. En el cultivar Hass, el compuesto foliar volátil dominante es el $\beta$-cariofileno; el estragol está ausente o en muy bajas proporciones (Espinosa-García et al., 2001). La distinción química concuerda geográficamente con las diferencias en la altitud de origen de híbridos y árboles típicos de $P$. americana var. drymifolia. Torres-Gurrola et al. (2009), también encontraron una distribución altitudinal diferente para el origen de los árboles con más de $60 \%$ de estragol y los que tenían cerca del $20 \%$ de este compuesto químico.

El hallazgo de un grupo numeroso de accesiones con características híbridas que tiene orígenes altitudinales menores que los árboles típicos de aguacate criollo, sugiere que mucha de la variación genética hasta ahora atribuida a la variedad criolla, en realidad proviene de hibridaciones ocurridas en las zonas de contacto de esta variedad con otras variedades o con $P$. schiedeana. Los contactos entre variedades posiblemente se dieron después de que las variedades evolucionaron separadamente (Chen et al., 2009) y después que ocurrieron varios eventos de domesticación por pueblos precolombinos (Galindo-Tovar et al., 2008) y de que hubo intenso comercio e intercambio de frutos en la época precolombina y en la colonial (GalindoTovar et al., 2008).

Localización geográfica de los grupos. La mayoría de las accesiones se encuentran en la Faja Volcánica Trans-Mexicana, área donde se concentran la mayoría de los recursos genéticos de este aguacate (Sánchez-Pérez, 1999). La mayor variación química en la Faja Volcánica Trans-Mexicana también fue observada en el banco de germoplasma de Celaya (Torres-Gurrola et al., 2009). En cuanto a la distribución de las variantes químicas típicas del aguacate criollo (grupos B2-1 y B2-2), encontramos que ambas coexistían en la Faja Volcánica Trans-Mexicana, pero que la variante B2-2 se encontraba sola en la fracción de la sierra Madre Oriental correspondiente al norte de Veracruz, Tamaulipas y Nuevo León, en la vertiente del golfo, y en Aguascalientes, Jalisco y Oaxaca, del lado del Pacífico. Una posibilidad de explicar esta distribución es que la variante B2-2 fue llevada a estos estados por el ser humano debido a alguna característica como el sabor, pues la concentración promedio de estragol en esos árboles (64\%) es menor que la concentración de los árboles del grupo B2-1 (80\%). Otra posibilidad es que los árboles de la variante B2-2 podrían tener un intervalo de tolerancia mayor a las condiciones climáticas que la otra variante, y que su presencia en esos estados ocurrió por medio de diseminación natural. Uno de los problemas de los bancos de germoplasma de aguacate de Michoacán es la poca o nula representación de los aguacates criollos de Chiapas. Sería deseable que hubiera más accesiones de estos estados para caracterizar sus variantes químicas.

Persea americana var. drymifolia presenta una gran diversidad genética (Ben-Ya'acov et al., 1992a; Chen et 
al., 2009; Cuiris et al., 2009) y química (Torres-Gurrola et al., 2009), ya sea en sus variantes híbridas o típicas. Este trabajo sugiere que en los bancos de germoplasma INIFAP de Michoacán, existe una gran diversidad química y por lo tanto genética, ya que los terpenos muestran un fuerte control genético (Rehfeldt, 1999; Adams, 2000; Otto y Wilde, 2001; Sabor y Skrzyszewaska, 2002; Adams et al., 2003; Nava-Cruz et al., 2006; Keszei et al., 2010), por lo que los bancos deben seguir conservándose $\mathrm{y}$ aumentando su tamaño para cubrir todas las zonas donde crece el aguacate criollo.

Se recomienda continuar recolectando material sobresaliente del país para mejorar la colección y mantener el ya existente en los bancos de germoplasma. También se recomienda continuar con trabajos de caracterización química y relacionarla experimentalmente con la resistencia a plagas y enfermedades para mejorar la producción y calidad del aguacate.

\section{Agradecimientos}

Al Dr. Ignacio Vidales Fernández, jefe del Campo experimental Uruapan, por permitirnos el acceso a los bancos de germoplasma. Asimismo, a las siguientes personas: Geóg. Jesús Fuentes Junco, Biól. Yolanda García R., M.C. Guadalupe Torres G., QFB Yurixhi Maldonado, Biól. Ángel Bravo, QFB Saúl Bernabé, Dr. Santiago Arizaga, M.C. Heberto Ferreira e Ing. Alberto Valencia, por su ayuda técnica en varios aspectos. Esta investigación fue financiada por el Centro de Investigaciones en Ecosistemas, UNAM (POFJE) y el Consejo Nacional de Ciencia y Tecnología a través del Proyecto 34895-V otorgado a FJEG.

\section{Literatura citada}

Adams, R. P. 2000. Systematics of the one seeded Juniperus of the eastern hemisphere based on leaf essential oils and random amplified polymorphic DNAs (RAPDs). Biochemical Systematics and Ecology 28:529-543.

Adams, R. P., A. E. Schwarzbach y R. N. Pandey. 2003. The concordance of terpenoid, ISSR and RAPD markers, and ITS sequence data sets among genotypes: an example from Juniperus. Biochemical Systematics and Ecology 31:375387.

Ben-Ya'acov, A., L. López-López, E. De La Cruz-Torres y A. F. Barrietos-Priego. 1992. A study of avocado germoplasma resources, 1988-1990. II. Findings from the central part of México. Proceedings of Second World Avocado Congress,
April 21-26, 1991, Orange California, University of California/California Avocado Society, Riverside. p.543-544

Ben-Ya'acov, A., M. Solis y E. Peri. 1995. Progress of the study of avocado genetic resources II. The avocado genetic resources in Costa Rica. Program and book of abstracts of the III World Avocado Congress, October 22-27, 1995, Tel Aviv. 109 p.

Bergh, B. O., R. W. Scora y W. R. Storey. 1973. A comparison of the leaf terpenes in Persea subgenus Persea. Botanical Gazette 134:130-134.

Bravo-Monzón, A. E. y F. J. Espinosa-García. 2008. Volatile emissions in Persea americana in response to the stem borer Copturus aguacatae attack. Allelopathy Journal 21:165-174.

Campos-Rojas, E., T. Terrazas y L. López-Mata. 2006. Persea (avocados) phylogenetic analysis based on morphological characters: of species relationships. Genetic Resources and Crop Evolution DOI 10:1007/s10722-005-3808-x.

Cates, R. G. y R. A. Redak. 1988. Variation in the terpene chemistry of Douglas-fir and relationship to Western spruce budworm success. In Chemical mediation of coevolution, K.C. Spencer (eds.). Academic, San Diego, California. p. 317-344.

Chen, H., V. Morrell, E. T. M. Ashworth, M. de la Cruz y M. T. Clegg. 2009. Tracing the geographic origins of major avocado cultivars. Journal of Heredity 100:56-65.

Cuiris-Pérez, H., H. Guillén-Andrade, M. E. Pedraza-Santos, J. López-Medina y L. Vidales-Fernández. 2009. Genetic variability within Mexican race avocado (Persea americana Mill.) germoplasm collections determined by ISSRs. Revista Chapingo Serie Horticultura 15:169-175.

Edwards, P. B., W. J. Wanjura y W. V. Brown. 1993. Selective herbivory by Christmas beetles in response to intraspecific variation in Eucalyptus terpenoids. Oecologia 95:551-557.

Espinosa-García, F. J. 2001. La diversidad de los metabolitos secundarios y la teoría de la defensa vegetal. In Relaciones químicas entre organismos. Aspectos básicos y perspectivas de su aplicación, A.L. Anaya, F.J. Espinosa-García, R. CruzOrtega (eds.). Universidad Nacional Autónoma de México y Plaza y Valdés. México, D.F. p.231-249

Espinosa-García, F. J., Y. García Rodríguez, F. Chávez Zavala, A. Chávez Zavala y G. Delgado. 2001. Implicaciones de la variación en los fenotipos químicos de las poblaciones de plantas en su susceptibilidad a plagas y patógenos: el caso de Persea americana var. Hass. In Memorias del 1er. Congreso Mexicano y Latinoamericano del Aguacate, octubre 16-21. Uruapan, Michoacán, México. 46-57 p.

Fiedler, J., G. Bufler y F. Bangerth. 1998. Genetic relationships of avocado (Persea americana Mill.) Using RAPD markers. Euphytica 101:249-255.

Furnier, G. R., M. P. Cummings y M. T. Clegg. 1990. Evolution of the avocados as revealed by DNA restriction fragment variation. Journal Heredity 81:183-188. 
Galindo-Tovar, M. E., N. Ogata-Aguilar y A. M. ArzateFernández. 2008. Some aspects of avocado (Persea americana Mill.) diversity and domestication in Mesoamerica. Genetic Resources and Crop Evolution 55:441-450.

Goralka, R. J. L., M. A. Schumaker y J. H. Langenheim. 1996. Variation in chemical and physical properties during leaf development in California bay tree (Umbellularia californica): Predictions regarding palatability for deer. Biochemical Systematics and Ecology 24:93-103.

Gouyon, P. H., P. Fort y G. Caraus. 1983. Selection of seedlings of Thymus vulgaris by grazing slugs. Journal of Ecology 71:299-206.

Hartmann, T. y B. Dierich. 1998. Chemical diversity and variation of pyrrolizidine alkaloids of the senecionine type: biological need or coincidence?. Planta 206:443-451.

Keszei, A., Y. Hassan y W. J. Foley. 2010. A biochemical interpretation of terpene chemotypes in Melaleuca alternifolia. Journal of Chemical Ecology 36:652-661.

Lahav, E. y U. Lavi. 2002. Genetics and classical breeding. In The avocado. Botany, production, and uses, A. Whiley. B. Schafler y B. Wolstenholome (eds.). CABI, Wallingford. 36-69.

Langenheim, J. H. 2003. Ecological roles of resins. In Plant resins: chemistry, evolution, ecology, and ethnobotany, Timber Press Science. Portland, Oregon. p.196-253

Langenheim, J. H., C. A. Macedo, M. K. Ross y W. H. Stubblebine. 1986. Leaf development in the tropical leguminous tree Copaifera in relation to microlepidopteran herbivory. Biochemical Systematics and Ecology 14:51-59.

Langenheim, J. H., C. E. Foster y R. B. McGinley. 1980. Inhibitory effects of different quantitative compositions of Hymenaea leaf resins on a generalist herbivore Spodoptera exigua. Biochemical Systematics and Ecology 8:385-396.

Linhart, Y. B. 1991. Disease, parasitism and herbivory: multidimensional challenges in plant evolution. Trends in Ecology and Evolution 6:392-396.

Mhameed, S., D. Sharon, D. Kaufman, E. Lahav, J. Hillel, C. Degani y U. Lavi. 1997. Genetic relationships within avocado (Persea americana Mil) cultivars and between Persea species. Theoretical and Applied Genetics 94:279-286.

Mijares Oviedo, P. y L. López-López. 1998. Variedades de aguacate y su producción en México. Memoria. Fundación Salvador Sánchez Colin-CICTAMEX, Coatepec Harinas, Estado de México. p. 22-32.

Nava-Cruz, Y., F. J. Espinosa-García y G. R. Furnier-Whitelaw. 2006. Levels and patterns of chemical variation in leaf resins of the genus Abies from northern México. Agrociencia 40:229-238.

Ogunbinu, A. O., I. A. Ogunwande, G. Flamini y P. L. Cioni. 2007. Volatile compounds of Persea americana Mill. from Nigeria. Journal of Essential Oil Searning Plants 10:133-138.

Otto, A. y V. Wilde. 2001. Sesqui-, di-, and triterpenoids as chemosystematic markers in extant conifers-a review.
Botanical Review 67:171-238.

Padalia, R. C., S. C. Joshi, D. S. Bisht y C. S. Mathela. 2009. Essential oil composition of Persea duthiei. Chemistry of Natural Compounds 45:745-747.

Penrose, L. W. 1953. Distance, size and shape. Annals of Eugenics 18:378-443.

Popenoe, W. 1941. The avocado a horticultural problem. Tropical Agriculture 183-11.

Popenoe, W. 1952. Central American fruit culture. Ceiba 1:222-227.

Rehfeldt, G. E. 1999. Systematics and genetics structure of Washoe pine: applications in conservation genetics. Silvae Genetica 48:167-173.

Rice, R. L., D. E. Lincoln y J. H. Langenheim. 1978. Palatibility of monoterpenoid compositional types of Satureja douglassi to a generalist molluscan herbivore, Ariolimax dolichophallus. Biochemical Systematics and Ecology 6:45-53.

Rincón-Hernández, C. A. 2005. Relación entre la diversidad química de las hojas del aguacatero criollo (Persea americana var. drymifolia) y la incidencia del agallero de las hojas (Trioza anceps Tuthill). Tesis, Facultad de Químico Farmacobiología, Universidad Michoacana de San Nicolás de Hidalgo, Morelia. Michoacán. 76 p.

Rincón-Hernández, C. A. y F. J. Espinosa-García. 2008. Relationship between the phytochemical diversity in creole avocado (Persea americana var. drymifolia) leaves and the incidence of foliar gall psyllid (Trioza anceps). Allelopathy Journal 21:175-182.

Sabor, J. y K. Skrzyszewska. 2002. The role of genetic terpene markers in selection and taxonomy of forest tree species. Part I. Chemistry and synthesis. Scope of application. (Polish) Sylwan 146:41-48. In Cambridge Abstracts in Biology AN: 20033004253.

Sagrero-Nieves, L. J. y P. Bartley. 1995. Volatile Components of avocado leaves (Persea americana Mill.) from the Mexican race. Journal of the Science of Food and Agriculture 67:4951.

Sánchez-Pérez, J. L. 1999. Recursos genéticos de aguacate (Persea americana Mill.) y especies afines en México. Revista Chapingo Serie Horticultura 5:7-18.

Savage, T. J., M. W. Hatch y R. Croteau. 1994. Monoterpene synthases of Pinus contorta and related conifers. The Journal of Botanical Chemistry 296:4012-4020.

Scora R. W. y P. E. Scora. 1998. Leaf oils of two new avocado varieties endemic to Costa Rica. Journal of Essential Oil Research 10:705-707.

Scora, R. W. y B. O. Bergh. 1992. Origin of and Taxonomic relationships within the genus Persea. In Proceedings of the Second World Avocado Congress, April 21-26, 1991, Orange California, University of California/California Avocado Society, Riverside. p.505-514

Scora, R. W. y P. E. Scora. 2000. Essential oils of Persea subgenus Persea (Lauraceae). Journal of Essential Oil 
Research 12:709-713.

Smith, R. H. 1983. Monoterpenes of logpeople pine xylem resin: A regional study in western United States. Forest Science 29:333-340.

Sturgeon, K. B. 1979. Monoterpene variation in ponderosa pine xylem resin related to western pine beetle predation. Evolution 33:803-814.

Torres-Gurrola, G., S. Montes-Hernández y F. J. EspinosaGarcía. 2009. Patrones de distribución y variación geográfica de los fenotipos químicos foliares de Persea americana var. drymifolia. Revista Fitotecnia Mexicana 32:19-30.

van der Werff, H. 2002. A synopsis of Persea (Lauraceae) in Central America. Novon 12:575-586.

Wu, H., C. Choul, T. L. Chang y I. Z. Chen. 2007. Genetic relationship estimation of Taiwan avocado cultivars by volatile constituents of leaves. Proceedings VI World Avocado Congress, Viña del Mar, Chile, 12-16 de noviembre 2007. p.1-14. 